\title{
Dinâmica hidrossedimentológica de duas sub-bacias hidrográficas localizadas no Estado do Tocantins
}

\author{
Hydrosedimentological dynamics of two sub-basins \\ located in the State of Tocantins, Brazil
}

Thaiana Brunes Feitosa ${ }^{[a]}$, Caroline lost ${ }^{[b]}$

[a] Bolsista do $\mathrm{CNPq}^{1}$, graduanda em Engenharia Ambiental pela Universidade Federal do Tocantins, Palmas, T0 - Brasil, e-mail: thaianabrunes@gmail.com

[b] Mestre e Doutoranda em Engenharia Agrícola pela Universidade Estadual do Oeste do Paraná, professora e pesquisadora do Núcleo Estadual de Meteorologia e Recurso Hídricos da Fundação Universidade do Tocantins Palmas, TO - Brasil,

e-mail: carolineiost@yahoo.com.br

\section{Resumo}

Esta pesquisa objetivou analisar a dinâmica hidrossedimentológica de duas sub-bacias hidrográficas localizadas no Estado do Tocantins no período compreendido entre setembro de 2009 e agosto de 2010, correspondente a um ano hidrológico no Estado. Por meio de um Sistema de Informação Geográfica (SIG) foram determinadas as características morfométricas, os tipos de solo e os usos e ocupação do solo das sub-bacias. As precipitações mensais foram calculadas utilizando o método de Thiessen, e os resultados foram submetidos à análise estatística. Utilizaram-se dados de 21 campanhas de monitoramento hidrossedimentométrico na elaboração das curvas-chaves de vazão e sedimentos. A produção específica de sedimentos em suspensão foi classificada como baixa, com valores de $21,94 \mathrm{t} \cdot \mathrm{km}^{-2} \cdot \mathrm{ano}^{-1}$ para a sub-bacia do Rio Manuel Alves Grande, e de $25,05 \mathrm{t} \cdot \mathrm{km}^{-2} \cdot$ ano $^{-1}$ para a sub-bacia do Rio Manuel Alves Pequeno. A baixa declividade e a adequada cobertura vegetal de ambas as sub-bacias funcionam como defesas naturais, reduzindo assim a propensão a erosões. A partir da correlação das precipitações, vazões e descarga sólida de cada sub-bacia, pode-se observar que o material sólido transportado é diretamente relacionado com a quantidade de precipitações, e que sub-bacias com características morfométricas diferentes resultam em graus de interferência diferentes. A precipitação, a cobertura vegetal, o uso e ocupação do solo, o tamanho da área de drenagem e a declividade foram características decisivas para a baixa produção de sedimentos em suspensão nas sub-bacias.

Palavras-chave: Caracterização morfométrica. Monitoramento. Uso e ocupação do solo.

Produção de sedimentos. 


\section{Abstract}

This research aimed to analyze the hydrosedimentological dynamics of two sub-basins located in the State of Tocantins in the period between September 2009 and August 2010, which corresponds to a hydrological year in the State. The morphological characteristics, soil type, land cover and land use in the sub-basins were analysed using a Geographic Information System (GIS) database. Monthly precipitation was calculated by the Thiessen method, and results were statistically analyzed. Data obtained from 21 hydrosedimentological tracking campaigns were utilized to generate the flow rate and sediment rating curves. The specific suspended sediment generation was classified as low, reaching $21.94 \mathrm{t} \cdot \mathrm{km}^{-2} \cdot y r^{-1}$ for the Manuel Alves Grande river sub-basin and $25.05 \mathrm{t} \cdot \mathrm{km}^{-2} \cdot \mathrm{yr}^{-1}$ for the Manuel Alves Pequeno river sub-basin. Low slope combined with adequate tree cover in both sub-basins act as natural shields, minimizing soil erosion. Correlation studies between precipitation, flow rate and solid discharge of each sub-basin showed that the amount of carried solid material is directly related to precipitation and that sub-basins with different morphometric characteristics lead to different degrees of interference. Precipitation, tree cover, land cover, land use, size of the drainage area and the slope were decisive characteristics for reduced suspended sediment generation in the sub-basins.

Keywords: Morphometric characterization. Monitoring. Land-use and land-cover. Sediment production.

\section{Introdução}

Na América do Sul estão inseridos alguns dos maiores rios do mundo. A bacia do Rio Tocantins, com uma área de drenagem de $777.308 \mathrm{~km}^{2}$, é a quarta maior bacia fluvial do continente, depois das bacias do Amazonas, Orinoco e Paraná (LATRUBESSE; STEVAUX, 2006). O desenvolvimento social e econômico do Estado do Tocantins depende, entre outros fatores, do aproveitamento hidrelétrico de seus rios, da produção agrícola, do turismo, da pesca e da navegação, atividades que, todas elas, de alguma forma estão relacionadas aos processos erosivos.

0 avanço da agricultura e o consequente aumento da utilização do solo nesse setor de forma não planejada, com a remoção de sua cobertura vegetal e a subsequente exposição às intempéries, ocasionam alterações no meio natural, provocando aceleramento no processo de erosão do solo - que traz consequências negativas e por vezes desastrosas, graças à sua forte influência sobre o regime hidrológico e sedimentológico de uma bacia hidrográfica (BRANCO, 1998).

0 estudo e a compreensão dos fatores que integram o processo de erosão do solo e a quantificação das perdas de solo são de grande importância, pois servem como ponto de partida para elaboração de medidas que visem à maximização do uso dos recursos hídricos disponíveis, para que se possam evitar os efeitos negativos decorrentes da produção, transporte e deposição de sedimentos (BRANCO, 1998).

As bacias hidrográficas se configuram como uma das principais unidades de gerenciamento territorial e são áreas importantes para a conservação dos recursos naturais, sendo modeladas pelas condições geológicas e climáticas locais. As características morfométricas de uma bacia hidrográfica são elementos de grande importância em seu comportamento hidrológico, sendo de grande aplicação como indicadores do grau de vulnerabilidade da bacia a enchentes, inundações e erodibilidade, dentre outros (VILLELA; MATTOS, 1975).

Segundo Carvalho (2008), a produção de sedimentos depende de uma série de fatores naturais (precipitação, tipo de solo, relevo), mas é determinada pelo uso do solo. De acordo com o tipo de solo, seu uso e ocupação e as características morfométricas das bacias, é possível inferir sobre a tendência ao aporte de sedimentos.

0 presente trabalho teve como objetivo analisar a dinâmica hidrossedimentológica de duas sub-bacias hidrográficas localizadas no Estado do Tocantins, utilizando como partida as características físicas das sub-bacias, as precipitações médias, as descargas líquidas e sólidas da região e o uso e ocupação do solo, contribuindo assim para o planejamento e a gestão das bacias hidrográficas. 


\section{Materiais e métodos}

Localização e descrição das áreas de estudo

A área em estudo refere-se às sub-bacias dos rios Manuel Alves Grande e Manuel Alves Pequeno, ambos afluentes da margem direita do Rio Tocantins (Figura 1). As áreas adotadas para o estudo compreendem as áreas incrementais a partir das estações de monitoramento localizadas nos rios principais. 0 período de estudo é compreendido entre setembro de 2009 e agosto de 2010, correspondente a um ano hidrológico no Estado do Tocantins.

\section{Caracterização morfométrica}

Para a caracterização das sub-bacias utilizaram-se bases cartográficas digitais no formato vetorial shapefile (.shp) e matricial raster (.GRID/.TIN) e mapas obtidos na Secretária de Planejamento e Meio Ambiente do Estado do Tocantins (Seplan) e na Gerência de Estado de Planejamento e Desenvolvimento do Estado do Maranhão (Geplan). A área incremental, o perímetro, o comprimento do rio principal, o comprimento da bacia, o comprimento de todos os rios, a altitude máxima e mínima e declividade foram determinados utilizando o software ArcView. A partir desses, e com o auxílio do software Excel, determinou-se os demais índices utilizados nessa pesquisa: o coeficiente de compacidade foi determinado segundo Villela e Mattos (1975), o índice de circularidade foi calculado conforme Cardoso et al. (2006), o índice de sinuosidade, de acordo com Alves e Castro (2003), a densidade de drenagem, segundo Horton (1945) e a amplitude altimétrica, segundo Villela e Mattos (1975).

\section{Pedologia e uso e ocupação do solo}

Os mapas pedológicos e de uso e ocupação do solo, para cada sub-bacia, foram obtidos a partir da manipulação dos dados fornecidos pela Seplan utilizando o software ArcView. A Geplan forneceu os mapas pedológicos e de uso e ocupação do solo do Estado do Maranhão, o que possibilitou o complemento da área incremental da sub-bacia do Rio Manuel Alves Grande, que ultrapassa o limite do Estado do Tocantins.

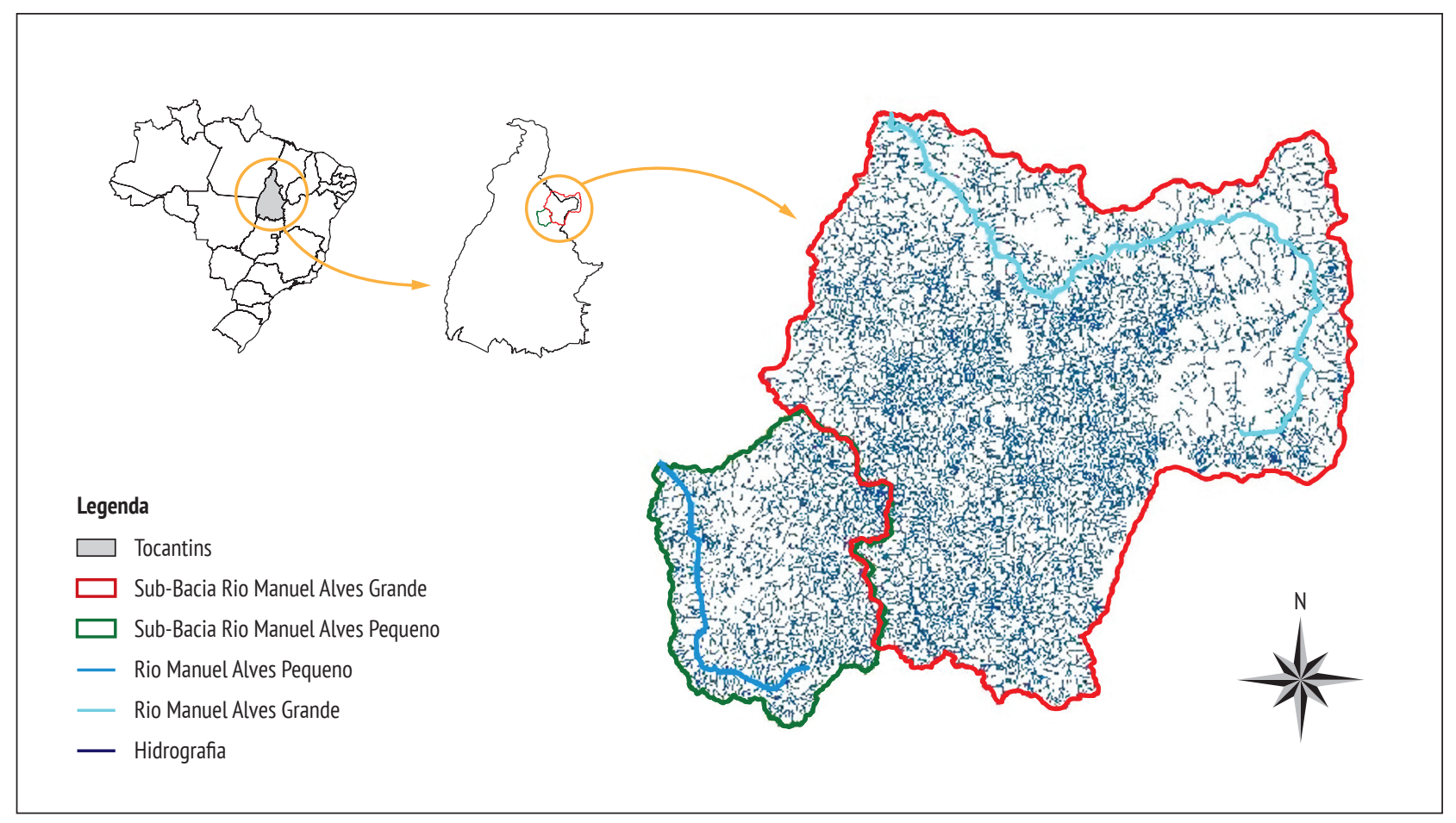

Figura 1 - Localização das sub-bacias dos rios Manuel Alves Grande e Manuel Alves Pequeno Fonte: Dados da pesquisa. 


\section{Precipitação}

Com uso do portal eletrônico da Agência Nacional de Águas (ANA) identificaram-se as estações pluviométricas que funcionam nas sub-bacias e áreas próximas e obtiveram-se os dados pluviométricos do período em estudo, submetendo-os à análise de consistência. Com o software AutoCAD, bases cartográficas digitais no formato vetorial shapefile (.shp) e pelo método de Thiessen, foram determinadas as áreas de influência de cada estação nas sub-bacias. As precipitações médias mensais para cada sub-bacia foram calculadas pela equação 1 :

$\mathrm{P}=\frac{\sum_{1}^{\mathrm{i}=1} \mathrm{~A}_{\mathrm{i}}+\mathrm{P}_{\mathrm{i}}}{\mathrm{A}}$

Em que:

$\mathrm{P}=$ precipitação média na sub-bacia $(\mathrm{mm})$;

$\mathrm{P}_{\mathrm{i}}=$ precipitação no posto $\mathrm{i}(\mathrm{mm})$;

$A_{i}=$ área do respectivo polígono, dentro da sub-bacia $\left(\mathrm{km}^{2}\right)$;

$\mathrm{A}=$ área incremental da sub-bacia $\left(\mathrm{km}^{2}\right)$.

A precipitação anual de cada sub-bacia foi comparada com a média de uma série de cinco anos de precipitações anuais das estações com área de influência dentro de cada sub-bacia, sendo esse o maior período coincidente disponível de dados das estações com áreas de influência dentro das sub-bacias, para verificação de possível normalidade dos dados.

Estimativa da descarga sólida de sedimentos em suspensão e produção de sedimentos

Os dados de cotas, vazões e concentrações de sedimentos em suspensão para o período em estudo foram fornecidos pelo Núcleo Estadual de Meteorologia e Recursos Hídricos (Nemet/RH - Unitins), que realiza o monitoramento hidrossedimentométrico nos rios principais das sub-bacias desde o ano de 2008.

A estação de monitoramento hidrossedimentológico da sub-bacia do Rio Manuel Alves Grande é a EHS Goiatins, localizada no município de Goiatins, com latitude $7^{\circ} 42^{\prime} 30,81$ "S, longitude $47^{\circ} 18^{\prime} 39,22$ "W, altitude igual a 169,724 m e código de registro na Agência Nacional de Águas (ANA) n. 23249000. A EHS
Itacajá está localizada no município de Itacajá, em latitude $8^{\circ} 23^{\prime} 29,08^{\prime \prime} \mathrm{S}$, longitude $47^{\circ} 45^{\prime} 56,93^{\prime \prime} \mathrm{W}$ e altitude 180 metros. A EHS Itacajá é a estação de monitoramento hidrossedimentológico do Rio Manuel Alves Pequeno, com código de registro na ANA n. 23150100.

Os dados coletados foram submetidos à análise de consistência, objetivando depuração e correção de erros e preenchimentos de falhas que possam interferir na análise. As leituras das réguas foram realizadas diariamente às $7 \mathrm{~h}$ e às $17 \mathrm{~h}$, e as outras medições mensalmente.

Com os dados das vazões e cotas foram elaboradas as curvas-chave de vazão de ambos os rios. Utilizaram-se dados de 21 campanhas de monitoramento realizadas entre maio de 2008 e agosto de 2010. A equação da curva-chave foi utilizada para transformar as cotas diárias em vazões diárias do período em estudo.

Para elaboração das curvas-chaves de sedimentos, primeiramente foram calculados os valores de descarga sólida em suspensão, utilizando-se a equação 2, descrita em Carvalho (2008):

Qss $=0,0864 \times \mathrm{Q} \times \mathrm{Css}$

Em que:

Qss = descarga sólida de sedimentos em suspensão $\left(\mathrm{t} \cdot \mathrm{dia}^{-1}\right)$;

Css = concentração de sedimentos em suspensão $\left(\mathrm{mg} \cdot \mathrm{L}^{-1}\right)$;

$\mathrm{Q}=\operatorname{vazão}\left(\mathrm{m}^{3} \cdot \mathrm{s}^{-1}\right)$.

Com os dados de vazões e da descarga sólida de sedimentos em suspensão foram elaboradas as curvas-chaves de sedimentos. As equações fornecidas pelas curvas foram utilizadas para obtenção das descargas sólidas em suspensão diárias. Finalmente, com as descargas sólidas em suspensão diárias puderam-se obter os valores mensais e anual de descarga sólida de sedimentos em suspensão para as sub-bacias em questão. A produção de sedimentos foi calculada pela equação 3, descrita em Carvalho (2008):

Pss $=$ Qss $/$ A

Em que:

Pss = produção de sedimentos em suspensão $\left(\mathrm{t} \cdot \mathrm{km}^{-2} \cdot \mathrm{ano}^{-1}\right)$; 
Qss = descarga sólida de sedimentos em suspensão $\left(\mathrm{t} \cdot \mathrm{ano}^{-1}\right)$;

$\mathrm{A}=$ área incremental da sub-bacia $\left(\mathrm{km}^{2}\right)$.

\section{Resultados e discussões}

\section{Caracterização morfométrica}

A sub-bacia do Rio Manuel Alves Grande é de sétima ordem e a sub-bacia do Rio Manuel Alves Pequeno é de sexta ordem. As características morfométricas estão apresentadas na Tabela 1.

A sub-bacia do Rio Manuel Alves Grande possui uma área incremental de $10.157,67 \mathrm{~km}^{2}$ e perímetro de $551,21 \mathrm{~km}$. 0 comprimento do rio principal é de $234,87 \mathrm{~km}$. A densidade de drenagem é de 1,13 $\mathrm{km} / \mathrm{km}^{2}$, indicando dessa forma que a sub-bacia possui baixa densidade de drenagem - como classifica Christofoletti (1969) as bacias com valores menores que $7,5 \mathrm{~km} / \mathrm{km}^{2}$.

A sub-bacia do Rio Manuel Alves Pequeno possui uma área incremental de $2.499,84 \mathrm{~km}^{2}$ e perímetro de $248,71 \mathrm{~km}$. 0 comprimento do rio principal é de $93,50 \mathrm{~km}$. A densidade de drenagem é de 1,12 km/ $\mathrm{km}^{2}$, indicando dessa forma que a sub-bacia também possui uma baixa drenagem.

Segundo Silva et al. (2010), valores baixos de densidade de drenagem estão geralmente associados a

Tabela 1 - Caracterização morfométrica das sub-bacias dos rios Manuel Alves Grande e Manuel Alves Pequeno

\begin{tabular}{lcc}
\hline $\begin{array}{l}\text { Parâmetros da } \\
\text { sub-bacia }\end{array}$ & $\begin{array}{c}\text { Rio Manuel } \\
\text { Alves Grande }\end{array}$ & $\begin{array}{c}\text { Rio Manuel } \\
\text { Alves Pequeno }\end{array}$ \\
\hline Área incremental & $10.157,67 \mathrm{~km}^{2}$ & $2.499,84 \mathrm{~km}^{2}$ \\
Perímetro & $551,21 \mathrm{~km}$ & $248,71 \mathrm{~km}$ \\
Comprimento do rio principal & $234,87 \mathrm{~km}$ & $93,50 \mathrm{~km}$ \\
Comprimento da bacia & $147,12 \mathrm{~km}$ & $69,13 \mathrm{~km}$ \\
Comprimento de todos os rios & $11.477,84 \mathrm{~km}$ & $2.812,34 \mathrm{~km}$ \\
Coeficiente de compacidade & 1,53 & 1,39 \\
Índice de circularidade & 0,42 & 0,51 \\
Índice de sinuosidade & 1,59 & 1,35 \\
Densidade de drenagem & $1,13 \mathrm{~km} / \mathrm{km}^{2}$ & $1,12 \mathrm{~km} / \mathrm{km}^{2}$ \\
Amplitude altimétrica & $488 \mathrm{~m}$ & $349 \mathrm{~m}$ \\
\hline
\end{tabular}

Fonte: Dados da pesquisa. regiões de rochas permeáveis e de regime pluviométrico caracterizado por chuvas de baixa intensidade ou pouca concentração da precipitação.

A sub-bacia do Rio Manuel Alves Grande possui um índice de sinuosidade equivalente a 1,59, indicando formas transicionais, regulares e irregulares. Já a sub-bacia do Rio Manuel Alves Pequeno apresentou um índice de sinuosidade equivalente a 1,35, indicando forma retilínea.

A Tabela 1 mostra que o coeficiente de compacidade de ambas as sub-bacias foi maior que 1 . Por meio desse resultado pode-se afirmar que as sub-bacias de drenagem, em condições normais de precipitação, ou seja, excluindo-se eventos de intensidades anormais, são pouco susceptíveis a enchentes. Também pelo coeficiente de compacidade verifica-se que a sub-bacia do Rio Manuel Alves Grande apresenta forma alongada. Tal fato pode, ainda, ser comprovado pelo índice de circularidade, uma vez que, segundo Müller (1953), os valores menores que 0,51 sugerem que as bacias tendem a ser mais alongadas, favorecendo o processo de escoamento, como é o caso da referida sub-bacia. Para o Rio Manuel Alves Pequeno, o índice de circularidade obtido foi de 0,51 , sugerindo uma forma tendendo a circular.

A classe de relevo predominante é o plano, conforme classificação da Embrapa (1979). A declividade influencia a relação entre a precipitação e o deflúvio da bacia hidrográfica, sobretudo em função do aumento da velocidade de escoamento superficial, reduzindo a possibilidade da infiltração de água no solo. Dessa forma, a baixa declividade atribui condições de maior resistência à ação da precipitação, atribuindo assim maior estabilidade.

\section{Pedologia e uso e ocupação do solo}

Na Tabela 2 constam as áreas e respectivos percentuais ocupados dentro de cada sub-bacia, referentes ao uso e ocupação do solo.

0 uso e ocupação do solo da sub-bacia do Rio Manuel Alves Grande apresentaram-se da seguinte maneira: 96,08\% da sub-bacia é composta por vegetação nativa (cerrado e mata ciliar) e as atividades agropecuárias correspondem a $0,56 \%$ da área total. Já na sub-bacia do Rio Manuel Alves Pequeno, o uso e ocupação do solo apresentaram-se com uma área correspondente a 99,15\% da sub-bacia composta 
por vegetação nativa, e as atividades agrícolas correspondem a apenas 0,55\% da área total. A grande área de vegetação nativa deve-se ao fato de que esta sub-bacia encontra-se dentro de uma área de uso legal restrito, uma área indígena.

Segundo Santos et al. (2000), o tipo de cobertura vegetal, presente numa área, tem grande influência sobre o escoamento superficial e a produção de sedimentos, pois a vegetação protege o solo contra o impacto da chuva, reduzindo assim o potencial de erosividade.

Apresentam-se na Tabela 3 as áreas e respectivos percentuais dentro de cada sub-bacia, referentes ao tipo de solo, conforme classificação da Embrapa (2006).

Na sub-bacia do Rio Manuel Alves Grande, há predominância do tipo de solo Neossolo, que ocupa $73,74 \%$ da sub-bacia. A presença desse solo de composição arenosa nas margens do rio atribui uma instabilidade muito grande, sendo um indicativo de

Tabela 2 - Uso e ocupação do solo das sub-bacias dos rios Manuel Alves Grande e Manuel Alves Pequeno

\begin{tabular}{lrrrrrr}
\hline & \multicolumn{2}{c}{$\begin{array}{c}\text { Manuel Alves } \\
\text { Grande }\end{array}$} & & \multicolumn{2}{c}{$\begin{array}{c}\text { Manuel Alves } \\
\text { Pequeno }\end{array}$} \\
\cline { 2 - 3 } \cline { 6 - 7 } Atividade & Área $\left.\mathbf{( k m}^{2}\right)$ & \% bacia & & \multicolumn{2}{c}{ Área $\left(\mathbf{k m}^{\mathbf{2}}\right)$} & \% bacia \\
\hline Vegetação nativa & $9.759,40$ & 96,08 & & $2.478,80$ & 99,15 \\
Atividade agrícola & 330,28 & 3,25 & & 13,66 & 0,55 \\
Pecuária & 57,21 & 0,56 & & 6,01 & 0,24 \\
Corpos hídricos & 10,39 & 0,10 & & 0,75 & 0,03 \\
Áreas urbanas & 0,38 & 0,01 & & 0,62 & 0,03 \\
\hline
\end{tabular}

Fonte: Dados da pesquisa.

Tabela 3 - Tipos de solo da sub-bacia dos rios Manuel Alves Grande e Manuel Alves Pequeno

\begin{tabular}{|c|c|c|c|c|}
\hline \multirow[b]{2}{*}{ Tipo de solo } & \multicolumn{2}{|c|}{$\begin{array}{c}\text { Manuel Alves } \\
\text { Grande }\end{array}$} & \multicolumn{2}{|c|}{$\begin{array}{c}\text { Manuel Alves } \\
\text { Pequeno }\end{array}$} \\
\hline & Área $\left(\mathrm{km}^{2}\right)$ & \% bacia & Área $\left(\mathrm{km}^{2}\right)$ & \% bacia \\
\hline Neossolo & $7.490,61$ & 73,74 & 150,38 & 6,02 \\
\hline Plintossolo & $1.473,18$ & 14,50 & $1.924,54$ & 76,99 \\
\hline Latossolo & $1.193,88$ & 11,76 & 424,92 & 16,99 \\
\hline
\end{tabular}

Fonte: Dados da pesquisa. futuros problemas de assoreamento na região. Segundo a Seplan (2011), em função da presença de solos arenosos nas margens do rio, grande parte dessa sub-bacia apresenta potencial para conservação ambiental.

A predominância na sub-bacia do Rio Manuel Alves Pequeno é do solo Plintossolo, que ocupa $76,99 \%$ da sub-bacia e, em conjunto com o Latossolo Amarelo, observável em 16,99\% dela, compõe as margens do rio. A margem esquerda tem predominância do Latossolo Amarelo, em geral, apresenta relevo suave, grande profundidade, alta permeabilidade e uma estrutura fina. A margem direita do rio é composta predominantemente pelo Plintossolo, que atribui estabilidade às margens do rio, reduzindo assim os processos de erosão naturais.

\section{Precipitação e valores estimados}

da produção da descarga sólida de sedimentos mensal para o período

Na Tabela 4, constam-se as precipitações médias e valores da descarga de sedimentos em suspensão para ambas as sub-bacias.

Foram identificadas sete estações pluviométricas que funcionam na região e áreas próximas. As estações com área de influência na sub-bacia do Rio Manuel Alves Grande foram Campos Lindos, Recursolândia, Itacajá, Palmeirante e Goiatins, e para a sub-bacia do Rio Manuel Alves Pequeno foram Recursolândia, Bom Jesus do Tocantins, Itacajá, Centenário e Goiatins.

A precipitação anual calculada para o período em estudo nas duas sub-bacias apresentou valores muito aproximados, indicando um regime de chuvas semelhante, o que se justifica pelo fato de as sub-bacias estarem localizadas muito próximas uma da outra. Para a sub-bacia do Rio Manuel Alves Grande, os meses que apresentaram maiores valores de precipitações foram dezembro e março, e para a sub-bacia do Rio Manuel Aves Pequeno os meses foram dezembro e abril.

A precipitação total anual das sub-bacias foi comparada com as médias anuais de cinco anos, compreendidos entre setembro de 2005 a agosto de 2010, das estações influentes. Para a sub-bacia do Rio Manuel Alves Grande a média da série obtida foi de $1.605,6 \mathrm{~mm}$, com valores oscilando entre $1.377,23$ 
Tabela 4 - Distribuição mensal da precipitação e descarga sólida de sedimentos em suspensão para as sub-bacias do Rio Manuel Alves Grande e Manuel Alves Pequeno

\begin{tabular}{|c|c|c|c|c|c|c|}
\hline \multirow[b]{2}{*}{ Meses $(2009 / 2010)$} & \multicolumn{3}{|c|}{ Manuel Alves Grande } & \multicolumn{3}{|c|}{ Manuel Alves Pequeno } \\
\hline & $(\mathrm{mm})$ & $\%$ & t/mês & $(\mathrm{mm})$ & $\%$ & t/mês \\
\hline Setembro & 23,63 & 1,52 & $2.496,23$ & 36,50 & 2,29 & 261,89 \\
\hline Outubro & 120,33 & 7,75 & $5.704,03$ & 112,40 & 7,04 & 407,05 \\
\hline Novembro & 56,83 & 3,66 & $5.352,09$ & 124,01 & 7,77 & 521,55 \\
\hline Dezembro & 329,77 & 21,24 & $27.251,73$ & 317,28 & 19,88 & $3.764,64$ \\
\hline Janeiro & 232,88 & 15,00 & $48.602,84$ & 266,89 & 16,72 & $7.333,72$ \\
\hline Fevereiro & 117,39 & 7,56 & $18.264,37$ & 192,17 & 12,04 & $2.500,74$ \\
\hline Março & 326,17 & 21,01 & $38.443,61$ & 236,00 & 14,79 & $7.174,94$ \\
\hline Abril & 285,31 & 18,38 & $60.287,59$ & 273,06 & 17,11 & $38.875,84$ \\
\hline Maio & 48,16 & 3,10 & $8.049,33$ & 32,56 & 2,04 & 883,34 \\
\hline Junho & 9,12 & 0,60 & $4.011,48$ & 1,37 & 0,09 & 454,80 \\
\hline Julho & 0,25 & 0,02 & $2.521,56$ & 3,20 & 0,20 & 278,62 \\
\hline Agosto & 2,52 & 0,16 & $1.882,06$ & 0,54 & 0,03 & 281,84 \\
\hline Anual & 1552,31 & 100 & $222.866,93$ & 1595,99 & 100 & $62.738,98$ \\
\hline
\end{tabular}

Fonte: Dados da pesquisa.

mm e 1.763,13 mm. A precipitação total anual, calculada pela equação 1 , corresponde a $1.552,3 \mathrm{~mm}$, apresentando-se entre as precipitações médias máximas e mínimas. Na sub-bacia do Rio Manuel Alves Pequeno a média obtida foi $1.570,65 \mathrm{~mm}$, com valores entre $1.475,176 \mathrm{~mm}$ e $1.864,7 \mathrm{~mm}$, a precipitação total anual, calculada pela equação 1 , corresponde a $1.595,99 \mathrm{~mm}$, apresentando-se entre as precipitações máximas e mínimas do período comparado.

A produção específica de sedimentos em suspensão da sub-bacia do Rio Manuel Alves Grande corresponde a $21,94 \mathrm{t} \cdot \mathrm{km}^{-2} \cdot \mathrm{ano}^{-1}$, e a da sub-bacia do Rio Manuel Alves Pequeno, a 25,05 t $\mathrm{km}^{-2} \cdot \mathrm{ano}^{-1}$. Segundo a Organização Meteorológica Mundial (WMO, 2007), pode-se considerar os valores inferiores a $35 \mathrm{t} \cdot \mathrm{km}^{-2} \cdot$ ano $^{-1}$ como valores aceitáveis e indicativos de baixa produção de sedimentos nas regiões. De acordo com Lima et al. (2003), quando esse índice é inferior a $70 \mathrm{t} \cdot \mathrm{km}^{-2} \cdot \mathrm{ano}^{-1}$, a produção de sedimentos da área de drenagem pode ser considerada baixa.

Melo et al. (2008) encontraram valores de produção de sedimentos em suspensão de 456,6 $\mathrm{t} \cdot \mathrm{km}^{-2}$. $\mathrm{ano}^{-1} \mathrm{em}$ uma pequena bacia hidrográfica do semiárido pernambucano. Para a bacia hidrográfica do Rio Wadi Abd na Algeria, Achite e Ouillon (2007) obtiveram um valor de produção de sedimento em suspensão de $136 \mathrm{t} \cdot \mathrm{km}^{-2} \cdot$ ano $^{-1}$ no semiárido africano. Valores de 43 a $135 \mathrm{t} \cdot \mathrm{km}^{-2} \cdot \mathrm{ano}^{-1}$ foram encontrados por Lima et al. (2004) ao longo da bacia do Rio Piquiri, cuja produção de sedimentos específica variou entre baixa e moderada.

Segundo Pereira et al. (2010), a produção de sedimentos depende de uma série de fatores naturais (chuva, solo, relevo), mas é determinada pelo uso do solo. De acordo com o tipo de solo, seu uso e ocupação e as características físicas das bacias, é possível inferir sobre a tendência ao aporte de sedimentos. Caiado (1994) concluiu, com relação aos sólidos carreados em suspensão, que a quantidade de sedimento transportada para os rios parece estar bem relacionada ao percentual da bacia que está sofrendo ações antrópicas.

Na sub-bacia do Rio Manuel Alves Grande, apesar da predominância do solo arenoso, o relevo plano e o grande percentual de vegetação da sub-bacia atenuam a instabilidade do solo arenoso, contribuindo para uma baixa produção de sedimentos, de $21,94 \mathrm{t} \cdot \mathrm{km}^{-2} \cdot$ ano $^{-1}$. A maior parte da área da sub-bacia é composta por vegetação nativa, no entanto, as atividades agropecuárias nas proximidades 
do rio podem contribuir para o gradual aumento da produção de sedimentos.

Não há infraestrutura viária e núcleos urbanos, e a ocupação, que entremeia as áreas serranas, é rarefeita, condicionada pelos solos muito pobres (Neossolo). A ausência de cuidados nesse caso pode propiciar a desertificação do solo da região. A extremidade sudeste dessa área, drenada pelo alto curso do Rio Manuel Alves Grande, apresenta características físicas e de ocupação diferenciadas. Ocorrem nessa área pastagens plantadas e culturas mecanizadas de soja. Ressalta-se a presença, entre a Chapada e o Rio Manuel Alves Grande, a Serra da Cangalha, área potencial para criação de Unidade de Conservação segundo levantamento feito pela Seplan. A baixa declividade, em conjunto com a boa cobertura vegetal de ambas as sub-bacias, funciona como defesas naturais, reduzindo assim a propensão a erosões.

O uso e ocupação do solo restringido e/ou inibido pela existência de uma área indígena contribuem para uma baixa produção de sedimentos na sub-bacia do Rio Manuel Alves Pequeno. A predominância do Plintossolo atribui uma estabilidade as margens do rio, reduzindo assim os processos erosivos naturais. No entanto, mesmo nessas condições, a sub-bacia apresentou uma produção de sedimentos pouco maior do que a do Rio Manuel Alves Grande. Essa diferença deve-se principalmente à precipitação: ambas as sub-bacias apresentam precipitação anual muito similar, porém a sub-bacia do Rio Manuel Alves Pequeno possui uma área incremental consideravelmente menor, sofrendo mais com a ação da chuva.

Observou-se a influência da precipitação nos resultados de descarga sólida mensal nos rios monitorados. Os meses que apresentaram maiores descargas sólidas correspondem aos meses mais chuvosos e, consequentemente, às maiores vazões médias. Esse resultado corrobora o que diz Carvalho (2008): 70\% a $90 \%$ do material transportado nos cursos d'água está diretamente relacionado com a quantidade de precipitações e ocorrem principalmente no período de fortes precipitações.

\section{Conclusão}

A análise estrutural das sub-bacias revela a diferenciação espacial existente entre elas e destaca o papel que as características morfométricas desempenham no potencial de armazenamento hídrico e no ciclo hidrológico de cada bacia. Pode-se observar que quantidades de precipitações similares em sub-bacias com características morfométricas diferentes apresentam graus de interferência diferentes. A baixa declividade e a boa cobertura vegetal de ambas as sub-bacias funcionam como defesas naturais reduzindo assim a propensão a erosões.

Com a análise do mapa pedológico das sub-bacias foi possível identificar regiões mais suscetíveis aos processos erosivos. Por meio da avaliação do uso e ocupação do solo, em relação à vegetação nativa, pode-se mostrar a atual situação de conservação e proteção dessas áreas.

Por meio da correlação das precipitações, vazões e descarga sólida de cada sub-bacia pode-se observar que o material transportado é diretamente relacionado com a quantidade de precipitações e ocorrem principalmente no período de fortes precipitações.

A precipitação, a cobertura vegetal, o uso e ocupação do solo, o tamanho da área de drenagem e a declividade são características decisivas para a baixa produção de sedimentos em suspensão nas sub-bacias. Destaca-se ainda que um dos fatores que podem vir a alterar a dinâmica na produção de sedimentos é o avanço da fronteira agrícola, sendo a ação antrópica o principal agente que conduz aos processos erosivos.

\section{Referências}

ACHITE, M.; OUILLON, S. Suspended sediment transport in a semiarid watershed, Wadi Abd, Algeria. Journal of Hydrology, v. 343, n. 3/4, p. 187-202, 2007.

ALVES, J. M. P.; CASTRO, P. T. A. Influência de feições geológicas na morfologia da bacia do rio do Tanque (MG) baseada no estudo de parâmetros morfométricos e análises de padrões de lineamentos. Revista Brasileira de Geociências, v. 33, n. 2, p. 117-124, 2003.

AGÊNCIA NACIONAL DE ÁGUAS - ANA. Disponível em: $<$ http://www2.ana.gov.br/Paginas/default.aspx>. Acesso em: 5 mar. 2011.

BRANCO, N. Avaliação da produção de sedimentos de eventos chuvosos em uma pequena bacia hidrográfica rural de encosta. 1998. 135 f. Dissertação (Mestrado em Engenharia Agrícola) - Setor de Irrigação e Drenagem, Universidade Federal de Santa Maria, Santa Maria, 1998. 
CAIADO, M. A. C. Inter-relações entre ambientes e qualidade das águas do Rio Itapemirim. 1994. Dissertação (Mestrado em Engenharia Ambiental) - Universidade Federal do Espírito Santo, Vitória, 1994.

CARDOSO, C. A. et al. Caracterização morfométrica da bacia hidrográfica do rio Debossan, Nova Friburgo-RJ. Árvore, v. 30, n. 2, p. 241-248, 2006.

CARVALHO, N. O. Hidrossedimentologia prática. 2. ed. Rio de Janeiro: CPRM, 2008.

CHRISTOFOLETTI, A. Análise morfométrica de bacias hidrográficas. Notícia Geomorfológica, n. 18, p. 35-64, 1969.

EMPRESA BRASILEIRA DE PESQUISA AGROPECUÁRIA EMBRAPA. Serviço nacional de levantamento e conservação de solos. Súmula da 10. Reunião Técnica de Levantamento de Solos. Rio de Janeiro, 1979.

EMPRESA BRASILEIRA DE PESQUISA AGROPECUÁRIA EMBRAPA. Serviço Nacional de Levantamento e Conservação de Solos (Rio de Janeiro, RJ). Súmula da 10. Reunião Técnica de Levantamento de Solos. Rio de Janeiro: EMBRAPA, 1979. (Embrapa-SNLCS. Micelânea, 1).

GERÊNCIA DE ESTADO DE PLANEJAMENTO E DESENVOLVIMENTO DO ESTADO - GEPLAN. Disponível em: < http:// www.zee.ma.gov.br>. Acesso em: 15 abr. 2011.

HORTON, R. E. Erosional development of streams and their drainage basin: Hydrophysical approach to quantitative morphology. Geological Society of America Bulletin, v. 56, n. 3, p. 275-370, 1945.

LATRUBESSE, E. M.; STEVAUX, J. C. Características físico-bióticas e problemas ambientais associados à planície aluvial do rio Araguaia. Revista UnG - Geociências, v. 5, n. 1 , p. $65-73,2006$.

LIMA, J. E. F. W. et al. Diagnóstico do fluxo de sedimentos em suspensão na Bacia Araguaia-Tocantins. Planaltina, DF: Embrapa Cerrados; Brasília, DF: ANA; ANEEL, 2003.

LIMA, J. E. F. W. et al. Diagnóstico hidrossedimentológico da Bacia do rio Piquiri. Planaltina, DF: Embrapa Cerrados, 2004.
MELO, R. O. et al. Produção de sedimento em suspensão de uma típica bacia hidrográfica semi-árida. In: ENCONTRO NACIONAL DE ENGENHARIA DE SEDIMENTO, 8., 2008, Campo Grande. Anais... Porto Alegre: ABRH - Associação Brasileira de Recursos Hídricos, 2008.

MÜLLER, V. C. A quantitative geomorphology study of drainage basin characteristic in the Clinch Mountain Area. New York: Virginia and Tennesse. Dept. of Geology, 1953. n. 3, p. 30 .

PEREIRA, M. D. et al. Hidrodinâmica e transporte de material particulado em suspensão sazonal em um estuário dominado por maré: Estuário de Caravelas (BA). Revista Brasileira de Geofísica, v. 28, p. 427-444, 2010.

SANTOS, C. A. G. et al. Influência do tipo da cobertura vegetal sobre a erosão no semi-árido paraibano. Revista Brasileira de Engenharia Agrícola e Ambiental, v. 4, n. 1 , p. $92-96,2000$

SECRETARIA DE PLANEJAMENTO E MEIO AMBIENTE DO ESTADO - SEPLAN. Disponível em: <www.seplan.to.gov. br>. Acesso em: 15 abr. 2011.

SILVA, L. da et al. Caracterização geomorfométrica e mapeamento dos conflitos de uso na bacia de drenagem do Açude Soledade. Revista Brasileira de Geografia Física, v. 3, p. 112-122, 2010.

VILLELA, S. M.; MATTOS, A. Hidrologia aplicada. São Paulo: McGraw-Hill, 1975.

WORLD METEOROLOGICAL ORGANIZATION - WMO. Commission for basic systems. Extraordinary session. Abridged final report of the extraordinary session, Seoul 9-16 November 2003. Geneva: WMO, 2007. (WMONo. 1017).

Recebido: 30/05/2011 Received: 05/30/2011

Aprovado: 18/08/2011

Approved: 08/18/2011 